\title{
Retraction Note to: Ultra-High Strength and Ductile Lamellar- Structured Powder Metallurgy Binary Ti-Ta Alloys
}

\author{
YONG LIU,${ }^{1,3,4}$ SHENGHANG XU ${ }^{1}$ XIN WANG,${ }^{1}$ KAIYANG LI, ${ }^{1}$ \\ BIN LIU, ${ }^{1}$ HONG WU, ${ }^{1}$ and HUIPING TANG $^{2}$ \\ 1.-The State Key Laboratory of Powder Metallurgy, Central South University, Changsha \\ 410083, Hunan, People's Republic of China. 2.-The State Key Laboratory of Porous Metals, \\ Northwestern Institute of Nonferrous Metals, Xi'an 710012, Shanxi, People's Republic of China. \\ 3.—e-mail: yonliu@csu.edu.cn. 4._e-mail: yonliu11@aliyun.com
}

\section{Retraction to: \\ JOM, Vol. 68, No. 3, 2016 \\ https://doi.org/10.1007/s11837-015-1801-1}

The editors and authors have retracted the article, "Ultra-High Strength and Ductile Lamellar-Structured Powder Metallurgy Binary Ti-Ta Alloys" by Yong Liu, Shenghang Xu, Xin Wang, Kaiyang Li, Bin Liu, Hong Wu, and Huiping Tang (https://doi.org/10.1007/s11837-015-1801-1). This article was published in the March 2016 issue of $J O M$. Following publication, the authors found that the data reported in Fig. 11 are incorrect due to a hidden problem with their testing instrument. As a result of the error, a significant portion of the published article is incorrect. All authors agree to this retraction. 